\title{
A QUALITY CONTROL SYSTEM PROTOTYPE FOR DETECTING KNOT DEFECTS IN THE WOODEN PANEL MANUFACTURING
}

\author{
Özgür KILIÇ, Department of Computer Engineering, Muğla Sıtkı Koçman University, Turkey, ozgurkilic@mu.edu.tr
}

(iD) https://orcid.org/0000-0002-0970-2071)

Delikanlı Mertcan SUSUZ, Department of Computer Engineering, Muğla Sıtkı Koçman University, Turkey, mertcansusuz@gmail.com

(iD) https://orcid.org/0000-0003-0279-9314)

Barış Ethem SÜZEK*, Department of Computer Engineering, Muğla Sıtkı Koçman University, Turkey, barissuzek@mu.edu.tr

(iD) https://orcid.org/0000-0002-1521-4306)

Received: 22.10.2018, Accepted: 24.01.2019

*Corresponding author

Research Article

DOI: $10.22531 /$ muglajsci.473338

\begin{abstract}
Product quality has become a necessary goal for all manufacturers in today's competitive market. Product defects, not detected, cause financial damages and reputation loss for the manufacturer. These defects can be due to quality of the inputs or misuse of the good quality inputs during the manufacturing process. This is also the case for wooden panel manufacturing where elements are the basic input. It is possible to reduce the loss of the manufacturer by using a method that minimizes the human error in the inspection of the elements. In this study, we, first, identified the quality control problems of the wooden panel manufacturers and basic steps in the automated element quality control. We then developed a prototype for the detection of knots, the most common defects in wooden panels. This prototype, with $80.0 \%$ true positive (with knot defect) and $82.0 \%$ true negative (without knot defect) rates, performs close to accuracy rates of a quality control inspector. The element image library created during the development of the system made publicly available for use in similar studies. This prototype is expected to be developed to detect other wood defects and to be applied in the wooden panel manufacturing.
\end{abstract}

Keywords: Image processing, Defect detection, Wooden panel quality control, Knot defect

\section{AHŞAP PANEL ÜRETIMINDE BUDAK KUSUR TESPITİ İÇIN BİR PROTOTİP OTOMATIK ELEMENT KALITE KONTROL SİSTEMI}

\section{Özet}

Ürün kalitesi yakalamak günümüzün rekabetçi pazarında üreticiler için olmazsa olmaz bir hedef olmuştur. Ürün kusurları, farkedilmezse, üreticinin ekonomik zararına ve itibar kaybına neden olur. Bu kusurlar ürünün girdilerinin kalitesinden veya kaliteli girdilerin uygun bir biçimde kullanılmamasından kaynaklanabilmektedir. Ana girdisi element olan ahşap panel üretimi için de bu durum söz konusudur. Elementlerin kontrol işlemi sırasında insan hatasını en aza indirecek bir yöntem ile üreticinin kaybını azaltmak mümkündür. Bu çalışmada ahşap panel üreticilerinin karşı karşıya olduğu kalite problemlerini ve üretiminde otomatik element kalite kontrolündeki temel adımları belirledik. Daha sonra, ahşap panellerde en yaygın kusur olan budakların tespiti için bir prototip geliştirdik. Bu prototip, \%80,0 doğru pozitif(budak hatalı) ve \%82,0 doğru negatif(budak hatasız) tespit oranları ile bir kalite kontrol denetçisine yakın doğruluk oranında çalıştı. Sistemin geliştirilmesi sırasında oluşturulan element görüntü kütüphanesi benzer çalışmalarda kullanılabilmesi için kamuyla paylaşıldı. Bu prototipin, diğer ahşap kusurlarını da tespit edecek şekilde geliştirilmesi ve ahşap panel üretiminde uygulanması öngörülmektedir.

Anahtar Kelimeler: Görüntü işleme, Kusur tespiti, Ahşap panel kalite kontrolü, Budak kusuru

Cite

Kilic, O., Susuz, D.M., Suzek, B.E., (2019). “A Quality Control System Prototype for Detecting Knot Defects in the Wooden Panel Manufacturing", Mugla Journal of Science and Technology, 5(1), 24-33.

\section{Introduction}

Wooden panel is defined as a product made from small sized wooden blocks, namely, elements which are first glued with each other on the narrow edges to form longer pieces of wood, which are then glued on the wide edges [1]. Due to their striking superiority in comparison to other equivalent products, wooden panels gained popularity among domestic and international consumers. For instance, wooden market production in Turkey has spiked up to an annual production capacity of $40.000 \mathrm{~m}^{3}$, a notable increase in its market share in an effort to meet the demand in the country [2]. 
Sizes of the elements used in wooden panels generally range from $5 \times 5 \times 25 \mathrm{~cm}$ to $5 \times 5 \times 90 \mathrm{~cm}$ and in each wooden panel, elements obtained from the same tree types are used. If the defects on the elements are overlooked during the manufacturing process then the final product, which is the wooden panel, will have poor quality and this will adversely affect the marketability of the wooden panel. Therefore, elements having defects should be eliminated through a rigorous quality control process. Existing element quality control in wooden panel manufacturing plants is performed manually by human inspectors. Therefore, they are prone to errors due to environmental and personal factors. Furthermore, the whole production process is prone to delays due to potential absence of quality control inspectors due to personal or health reasons. Although training new quality control inspectors is an option, this takes time and investment.

Image processing techniques have been used in various fields to perform automated quality control without human intervention. These techniques are in use and becoming popular in the quality control of products such as textile [3-6], ceramic [7-9], steel [10,11], glass [12], electronic circuits[13], weld bead[14] , metal lids [15] and cylindrical parts [16] to keep up with high quality standards set by the competitive markets. There are also academic studies [17-22] on applying image processing techniques in the quality control of wooden surfaces.

There are existing quality control systems in the wider wood industry. EasyScan [23] by Weinig for lumber quality control; SuperScan [24] by Grecon and ColourBrain [25] by Baumer for quality control of laminate and furniture panels, are such quality control systems. There is no automated quality control system specific to elements used in wooden panel manufacturing. One option is the adaptation of these quality control systems to element quality control purpose. However the investment to do so is forbiddingly high for the wooden panel manufacturers in Turkey, given their size. The other option is a custom element quality control system tailored towards this particular need of wooden panel industry.

In this study, we, first, identified the quality control problems of the wooden panel manufacturers and basic steps in the automated element quality control. We then developed a prototype for the detection of knots, the most common defects in wooden panels. We envision this prototype will be extended to cover other type of wooden panel defects. Hence, this study aims to aid designing automated element quality control systems and improve the efficiency of quality control processes of wooden panel manufacturing industry.

The paper is organized as follows. Section 2 describes the process of wooden panel manufacturing and lists the issues related to quality control of elements. Section 3 gives a compilation of the basic steps in image processing applications for quality control, the challenges faced in these steps and possible solutions to them. In Section 4, our proposed system to detect knot defects is described. Finally, we discuss the performance of the system in Section 5 and the future enhancements in Section 6.

\section{Problem Description}

\subsection{Existing Manufacturing Process}

In wooden panel manufacturing, wooden blocks, namely elements, generally having a size ranging from $5 \times 5 \times 25$ $\mathrm{cm}$ to $5 \times 5 \times 90 \mathrm{~cm}$, are glued together to create a final product with a maximum size up to $6 \times 1.25$ meter. Wooden panels can be manufactured from various types of trees, however, a wooden panel should consist of elements originated from the same type of tree.

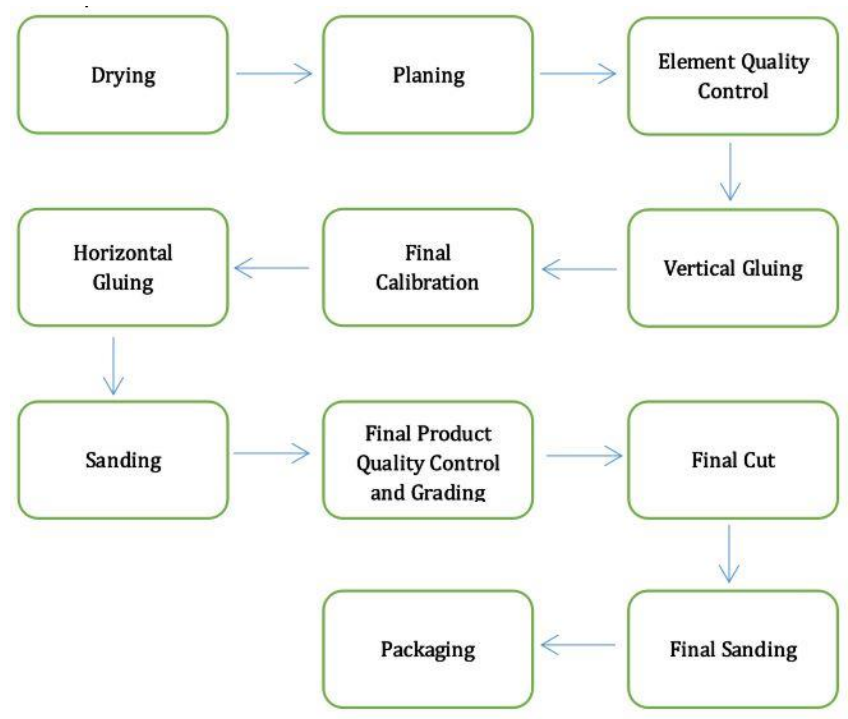

Figure 1. Wooden Panel Manufacturing Process.

Having elements as primary input, the steps of the wooden panel manufacturing process shown in Figure 1 are summarized as follows.

Drying: Elements are dried to minimize the moisture in them. After this step, elements become lighter, stronger and they will have more resistance to distortion.

Planing: Dried elements are planned to have smooth and flat surfaces. At the end of this step, each element has the identical width and thickness that are $48 \times 48$ $\mathrm{mm}$. The speed of the planing machine can reach to 11 $\mathrm{m} / \mathrm{min}$.

Element Quality Control: Each element processed by the planing machine is subject to following controls and classifications conducted by quality control inspectors:

$\checkmark \quad$ Size Control: Although the planing machine reduces the width and thickness of each element to uniform dimensions, some elements may originally have smaller dimensions than the target dimensions. If the width and the thickness of an element are below a threshold, it may introduce problems during the next steps and therefore it should be eliminated from the manufacturing process. If $\% 80$ of the length of an element is $2 \mathrm{~mm}$ smaller than 
the target size (48 $\mathrm{mm}$ ) in width or thickness then the element fails to pass the size control.

$\checkmark \quad$ Surface Defect Detection: If at least one surface of an element does not have any defect then the element will be eligible to proceed to the next step in the manufacturing process.

$\checkmark$ Color Classification: Elements from the same tree type may have different color tones. Having a mixture of color tones on the same wooden panel may have effects on the quality of the panel. For example, homogeneity is preferred for some of the trees such as oak and using elements having different color tones results in poor quality. On the other hand, heterogeneity is preferred for some of the trees such as walnut. During the color classification, elements are categorized into a few groups based on their color tones. In the case of homogeneity, elements from the same group are used in the next steps to form a wooden panel, otherwise, elements are selected evenly among the groups. Generally the elements are classified into three groups; light, middle and dark.

$\checkmark \quad$ Grain Classification: Elements may have different types of grains on their surfaces as a result of sawing pattern used. Having different types of grains on a wooden panel reduces the quality of panels. For instance in pine trees, two types of grains, straight and diagonal are defined and elements from pine trees are grouped into these types based on their grains. During the manufacturing, elements from the same group are selected to construct a wooden panel, that is, a panel consists of only either straight grained elements or diagonal grained elements.

Vertical Gluing: After successful completion of quality control phase elements are glued vertically by locating the non-defective surfaces in the same direction. In order to adhesion of glue the edges are shaped as finger joints. The output of this step is a stick called lamella with a length of 6.5-6.7 meters.

Final Calibration: The lamellae, output of the vertical gluing, are processed in the planing machine and their width and thickness are reduced to $42 \mathrm{~mm}$.

Horizontal Gluing: After the final calibration, lamellae are glued horizontally by having their non-defective surfaces on the same side. If the elements are subject to color or grain classification then lamellae are selected according to their groups in this step. As a result of this step, a crude panel is formed.

Sanding: In this step, sanding is applied to all surfaces of the panel.

Final Product Quality Control and Grading: In this step, panels are controlled manually for any defects on them and graded accordingly. Some minor defects can be corrected using filler materials.

Final Cut: Panels are reduced to final product size which is generally $1.25 \times 6$ (width $\mathrm{x}$ length) meters through the cutting process.
Final Sanding: To smooth the surface, the panel is sanded for the last time. The thickness of the panel becomes $40 \mathrm{~mm}$ after the sanding process.

Packaging: Panel is customized as per customer needs and packed. For instance if the panel is for a kitchen countertop, the holes for sink and faucet are cut.

\subsection{Quality Control Aspects}

Various types of defects may occur on the surface of elements which are the primary input for a wooden panel. Even a single defective element in a wooden panel affects the quality of the whole panel. Therefore the elements having defects on their surfaces should be eliminated carefully. The characteristics of defects should be described quantitatively and qualitatively for an effective quality control process regardless of the approach used; manual or automated. In addition, color and grain homogeneity (or heterogeneity depending on tree type) rules are needed. The quality criteria for the wooden panels described in following sections are based on TS11970/EN13990 [26] standard and definitions for the wood industry.

\subsubsection{Defects on Elements}

Knots: While the body of a tree becomes larger, some portions of the branches are included in it and become knots which are considered as defects weakening the structure and the strength of wood products [27]. In addition, knots also affect the color uniformity on a surface and result in poor product quality. Knots are generally classified as follows according to their sizes and structures.

$\checkmark \quad$ Sound Knot: It has almost the same strength as the wood it is located in and is darker in color. It should not be present on the visible surface of the wooden panel.

$\checkmark \quad$ Loose Knot: It is the part of a dead branch stayed inside the body of a tree and therefore is not well integrated with it. Hence it may drop from the lumber at any time. It should not be present on the visible surface of the wooden panel.

$\checkmark \quad$ Pin Knot: It is a sound knot having a diameter less than $12 \mathrm{~mm}$. On a 1 meter square of the wooden panel only a single pin knot is allowed.

Worm hole: It is a tunnel or a passage in a wood produced by worms.

Crack: Wood is a material that can shrink as its moisture level decreases and expand as its moisture level increases. Cracks are usually the result of an improper drying process in which the inner and outer parts of the wood have different moisture levels.

Medullary Rays: They are lines from the core of tree trunk to the outside. Medullary rays are perpendicular to the growth rings. Although these rays are not accepted as a defect, having too many rays on the surface adversely affects visual appearance and appeal of the wooden panel. 
Discoloration and Stains: Fungal damage on the tree body may result in discoloration. If a timber is exposed to moisture or is stored in unfavorable conditions in a timber yard, this will also cause discoloration, which is to be strictly avoided on the visible surface of the wooden panel.

Sapwood: Being close to the crust of the tree body, this layer is live and is lighter in color in comparison to the inner layers, so it distorts the color uniformity. This is why this part should be avoided on the visible part of the wooden panel.

Wane: Wane is wood missing or bark (from the outer layer of the tree) from the edge of an element. For an element to be used in production, the wane width should be no more than $1 \mathrm{~mm}$.

Size Defect: Wooden panel manufacturing requires uniformity and consistency in the size of elements. For instance, the initial size of the element, which is normally $48 \times 48 \mathrm{~mm}$ (width $\mathrm{x}$ height), is reduced down to $40 \times 40 \mathrm{~mm}$ through the steps followed in manufacturing process (Figure 1). To produce uniformity elements of $40 \times 40 \mathrm{~mm}$, the initial size should be consistent at $48 \times 48 \mathrm{~mm}$ throughout the length of the element, which is hardly the case. Yet, the manufacturing process tolerates size discrepancies to a certain level; the initial width and thickness of an element should be at least $48 \times 48 \mathrm{~mm}$ for at least through $20 \%$ of its length and the remaining $80 \%$ of the element should not be at least $46 \times 46 \mathrm{~mm}$.

\subsubsection{Color Tone and Grain Mixture}

Color Tone Mixture: An important factor to determine the quality of the end product in wooden panel manufacturing is the mixture of color tones. The desired mixture of color tones is dependent on the tree type. While color tone homogeneity is sought in oak panels, heterogeneity, in other words mixing elements in different color tones, is more preferable in walnut panels. To meet these criteria, the elements are first grouped based on their color tones requirements.

Grain Homogeneity: In the pine panels, uniform surface patterns are sought after. Hence, prior to gluing pine elements are grouped into ripple or straight lines based on their surface patterns Elements sharing similar patterns, along with color tones, are used in the manufacturing the panel to achieve surface uniformity.

\section{Basic Steps in Image Processing-based Quality Control}

Any defect element neglected during the element quality control process will adversely affect the quality of the end product; wooden panel. A human-based quality control system is typically error-prone due to personal and environmental factors. An automated quality control system, on the other hand, is reliable, consistent and subjective, so its qualities mitigate risks around financial and reputation losses companies may face due to quality problems. There are challenges around developing an automated element quality control system. These challenges and the solutions recommended in this study are summarized in the following subsections.

\subsection{Scanning Element Surfaces}

To utilize image processing techniques for identifying defects and distinguish defectless element surfaces, an image library should be created. Two major resources are needed to create this image library; 1) A scanner hardware to capture the element surface videos or images, and 2) A quality control inspector to label all the images in the library as defective and defectless.

The scanner hardware to capture element images should operate on or simulate the conveyor-belt in wooden panel manufacturing plans. This hardware should have a high-resolution camera to capture a surface image at high quality. The camera should not be affected by any factor, such as external light, that will distort images, introduce noise, and consequently mislead defect detection. Considering reflective nature of elements, the light sources for image capturing should be located and adjusted to minimize reflection and prevent introducing noise to image processing step. The color of the background that is scanned (e.g., the conveyor belt) should facilitate distinguishing the element surface and background.

Apart of from capturing, labeling images as defective or defectless is a critical task. Although there are various image libraries for wooden surfaces [28], there is no available library for elements used in wooden panel manufacturing. Thus, a library of element surface images needs to be compiled and labeled for their defects (knot, worm hole, crack, etc.) as a prerequisite to the development of an automated element quality control system. Element labeling task requires recruitment of quality control experts through a university-industry cooperation. In this study, the element surface images have been labeled as positive (with knot defect) and negative (without knot defect) by a quality control inspector.

For this study, to capture element surface images, a prototype scanner equipped with a high-resolution camera, is designed. The scanner is placed over a sliding system to mimic the horizontal motion of conveyor belts used in wooden panel manufacturing plants. The detailed methodology is explained in Section 4.1.

\subsection{Processing of Element Surface Videos}

As it is counterintuitive to stop production lines (e.g. conveyor belts) in wooden panel manufacturing plants and take single element surface shots, the camera on the scanner operated in should operate in video mode. The frames of element videos should then processed into many distinct element surface images.

Due to its thin and long shape, the element will only be captured partially in continuous video frames. Hence, the video frames covering the entire element surface needs to be selected and processed. This can be achieved following two approaches. In the first 
approach, overlapping video frames can be merged to produce a single image covering the entirety of the element surface using algorithms such as SIFT [29] implemented in OpenCV library [30]. In an analogous problem, an earlier study [31] had demonstrated how the entire image of a train can be constructed from a video using SIFT algorithm. In the second approach, video frames are first processed to identify the first and the last frames where a section of element surface is seen in its entirety as it enters and leaves the field of view (FoV) of the camera. Next, a subset of video frames between this first and last frame are selected in a sequential fashion ensuring representation of the complete element surface. For instance, if the camera's FoV can capture $12 \mathrm{~cm}$ of the element, to cover its entire $25 \mathrm{~cm}$ surface, three or more video frames are selected. In this second approach, if a defect is detected in any of the selected frames, the corresponding element surface will be classified as defective.

For the purposes of this study, the second approach is preferred as the first approach requires extra computation time to merge frames which takes away much needed time from defect detection. Furthermore, the errors, even minor, introduced by the image processing algorithm used in merging the frames could be classified as defects (false positives). The details of the application of the second approach are discussed in Section 4.2 .

\subsection{Application of Image Processing Techniques in Defect Detection on Wooden Surfaces}

Image processing techniques have been used in quality control processes of wooden surfaces. In an effort to differentiate a particular pattern during image processing, first, the characteristics or features of the pattern need to be defined. For instance, in a similar study [32] to detect knots on wooden surfaces, the features such as gray average, gray variance and eccentricity that may correlate with the presence of knot are used. Features of a pattern can be identified experimentally, as in the case of the study [32] or by statistical methods such as Gray Level Co-Occurrence (GLCM) [33]. GLCM takes into account the frequency of the appearance of pixel pairs that presents a relation between certain locational and gray tone value, then based on this relation establishes a matrix that defines the texture features on the image, and finally employs a feature-based classification. GLCM method was used in various studies to detect defects of wooden surfaces. For instance, utilizing GLCM matrixes to identify defects and to classify these, Conners [34] identified 6 features such as inertia, cluster shade, cluster prominence, local homogeneity, energy, and entropy and used Naïve Bayes classification. Another study [22] that aimed at the detection of sound and loose knot, calculated contrast feature only. In order to differentiate pixels of the faulty texture, the study used Otsu [35] method to specify the thresholds and applied a rule-based classification.
Another method to extract features is to use filters that are formed by means of utilizing Gabor Function [36]. Gabor function was initially defined as single-dimension and then was revised by Daugman [37] as to have 2 dimensions, which enabled image processing. Filters formed using Gabor function are called Gabor filters and these filters are used for purposes such as texture analysis, feature extraction, and edge detection. Gabor filters are the type of filters that allow the penetration of certain frequency range only and that would exclude those out of that particular range. The pixels that are most sensitive and thus easily picked by Gabor filters are those where the texture changes in the image and are especially the edge pixels within the texture.

Having been used for wooden surface defect detection purposes, Gabor filters were used by Mohan [21] and Chacon [38] in order to extract the features that will be used in knot classification. Mohan [21] carried out wood knot classification using the bagging technique by means of algorithms such as Naïve Bayes, RepTree, Random Forest and K Nearest Neighbor. Chacon [38] used algorithms such as Self Organizing Neural Network and Feed Forward Perceptron Neural Networks.

Haralick [33] has defined 14 features including characteristics such as energy, contrast, correlation, and homogeneity. In order to identify which values of these features correspond to what texture characteristics, Haralick utilizes a training image set and piecewise linear discriminant functions method. After trained and calculated using a training set, features are checked how successful they are in defining the texturecharacteristics.

For the purposes of this study, image blurring, image erosion, binarization through gray level thresholding were used to detect knots. The parameters of these techniques were identified experimentally. Section 4.3 of this paper explains the details of how these techniques are applied.

\section{Method}

Development of the knot defect detection system consists of three phases: element surface scanning, element surface video processing, and automated knot defect detection. During the element surface scanning, element surfaces with or without knot defects are obtained and labeled, accordingly. In addition, videos of these surfaces are captured. During the element surface video processing phase, the required number of images is selected from the captured videos to cover the whole surface of the element. During the automated knot defect detection phase, knot defect detection algorithm is executed for the selected images. Following subsections details our methodology.

\subsection{Scanning Element Surfaces}

In this phase, a total of 100 elements were obtained from a wooden panel manufacturing company in Muğla province of Turkey. These elements are labeled as defective (with knot defects) and defectless (without 
knot defects) elements by the quality control inspector of the company and used in the testing our methodology. A prototype scanner was designed and crafted to capture element surface videos. Figure 2 shows the design of this scanner that scans the upper surface of the element. The prototype scanner moves horizontally on a sliding system and thus simulates the conveyor belt mechanisms used in the real production environment of a wooden panel manufacturing plant. To easily differentiate the background from that of the element surface, the sliding systems' color was chosen as white. Comprised of a $30 \mathrm{~cm}$ long $10 \times 10 \mathrm{~cm}$ tunnel, and a $30 \mathrm{~cm}$ high $10 \times 10 \mathrm{~cm}$ tower in the middle of the tower, the prototype scanner is designed to eliminate any potential outside/external light effect during the video recording. A high-resolution camera (Sony Cybershot DSCW300) is projected vertically down from the top of the tower to capture element surface videos with speed of 30 frames per second. Due to tower height and FoV of the camera, each video frame contains $12 \mathrm{~cm}$ of the element surface in length (no limitation on width). The scanner is also equipped with two internal LED light sources. The location and angles of light sources were critical. Direct light causes glare on the element surface and this distorts captured video. On the other hand, insufficient light due to a wrong angle results in shadows and/or poor quality videos. Based on our experiments, positioning the two LED light sources in either tunnel entrances facing the tower horizontally gave the best video quality.
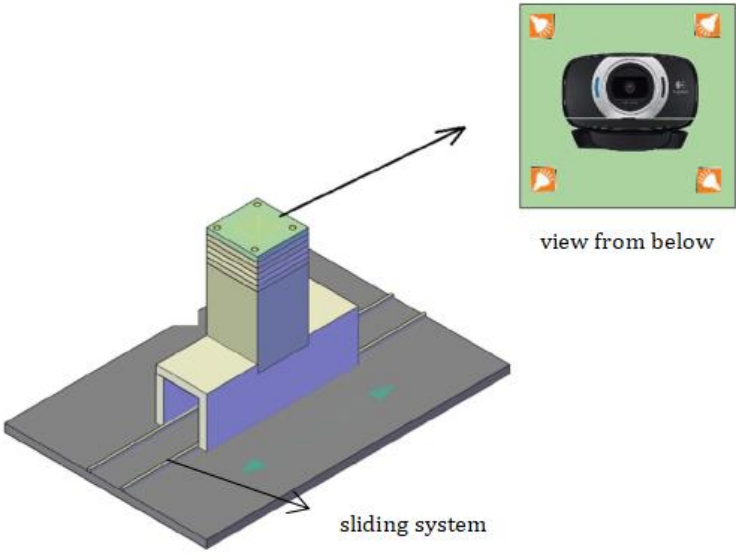

view from below

Figure 2. Prototype Scanner.

Finally, in this phase, the scanner is used to capture 100 element surface videos, 50 of which is with knot defect and the remaining is without knot defect. These videos are processed and prepared for detection in the following phase.

\subsection{Processing of Element Surface Videos}

An element surface video obtained from the prototype scanner (see Section 4.1) consists of 30 frames per second. Since each frame contains $12 \mathrm{~cm}$ of the element surface in length and the length of an element varies from $25 \mathrm{~cm}$ to $90 \mathrm{~cm}$, a single frame did not capture the entire surface of an element. Furthermore, some frames may partially contain the element surface when elements just begin to enter into or start leaving the camera's FoV. In Figure 3, three images extracted from the video of an element are shown. Image 60 shown in Figure $3 \mathrm{a}$ is the 60th frame of the video, image 80 shown in Figure $3 \mathrm{~b}$ is the 80th frame of the video and image 125 in Figure $3 \mathrm{~b}$ is the 125th frame of the video. In Figure $3 \mathrm{a}$ and Figure $3 \mathrm{~b}$ the element has just entered into the frame but does not span the frame from end-toend, therefore the white background is visible between the left edge of the frame and the left edge of the element. Similarly, while leaving the frame a gap is formed between the right edge of the frame and the right edge of the element. The image in Figure 3c displays a surface from right edge of the frame to the left edge of the frame and this image overlaps with the surface region displayed in Figure $3 \mathrm{a}$ and Figure $3 \mathrm{~b}$. There is no need to process frames which contain partial element surface since they are already contained in another frame. Furthermore, as seen in Figure 3, the amount of white background in frame 60 and frame 80 is much more than the frame 125 and having more background in an image introduces additional noise that can lead to false defect detection. Hence, the first step of video processing is to eliminate frames which contain partial element surfaces. In order to distinguish the element surface from the conveyor belt surface, elements are carried on a white colored belt.

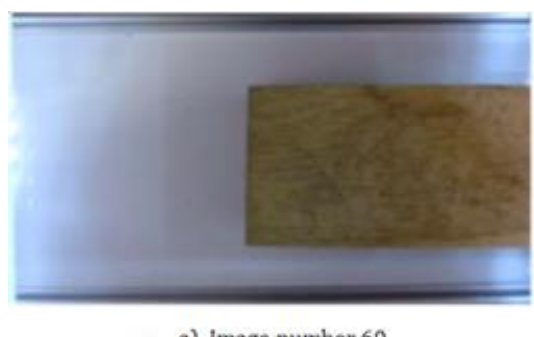

a) Image number 60

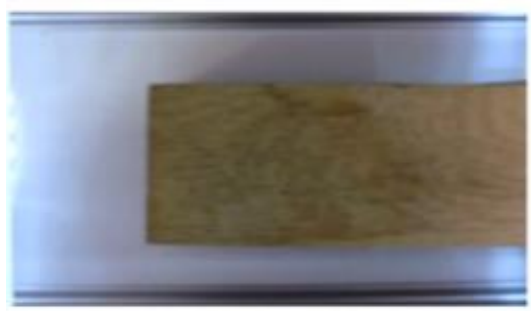

b) Image number 80

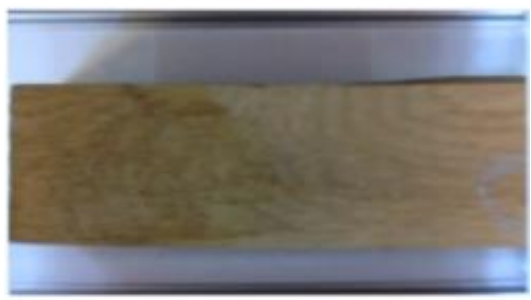

c) Image number 125

Figure 3. Image Flow. 
To detect the images containing partial surface, first, black and white conversion is performed on the images extracted from the video using a fixed threshold as shown in Figure 4. Rectangular white areas in right and left edges of video frames are used as indicators of partial element surface image and such frames are eliminated from the beginning (or end) of the video.

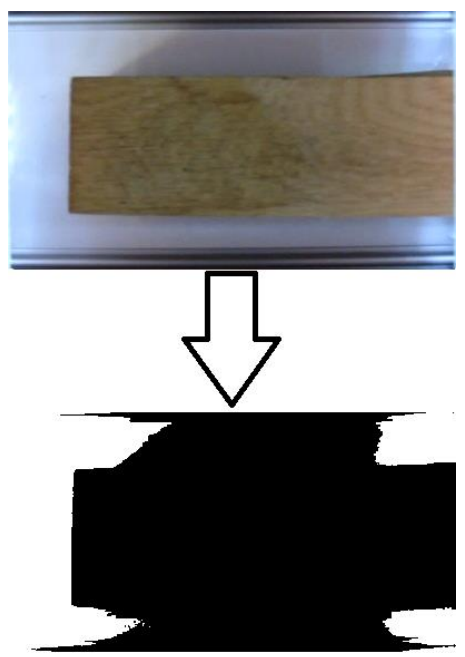

Figure 4. Image Extraction and Selection.

Given the video has 30 images per second, consecutive video frames have many overlapping regions. Hence, after eliminating the frames with partial element surface, from the remaining frames a subset of frames covering the full element surface is selected sequentially following the video frame order in equal intervals. As the selected frames are used for knot defect detection in next phase, the number of selected video frames must be large enough to cover whole element surface but small enough to improve knot detection by limit the number of frames processed. Although in a panel manufacturing plant, the interval between selected frames is dependent on and adjusted according to the conveyor belt speed, for practical purposes, in this study, ten equal-interval video frames including the first and last video frames containing a full element surface image are selected. Selected images are then passed to the knot defect detection phase.

\subsection{Automated Knot Defect Detection}

In this phase, knot defects on the frames from earlier step are detected and tagged in several steps; image smoothing, grayscaling, image erosion, histogram thresholding to identify knot defect candidates, knot defect classification, and finally tagging the knot. Figure 5 shows knot defect detection steps for an element surface image.

The first step; image smoothing, is a technique to minimize noise by convolving the image with a filter kernel. We tested various filters including Averaging, Median, Bilateral and Gaussian filters and various matrix dimensions. Gaussian smoothing yielded the best result with an $11 \times 11$ matrix. This smoothing step also reduced the adverse effect of minor camera focus problems, resulting in blurring on the original images, on knot detection. In Figure 5 Step 1, the smoothed version of an example element image after application of a Gaussian smoothing is shown.

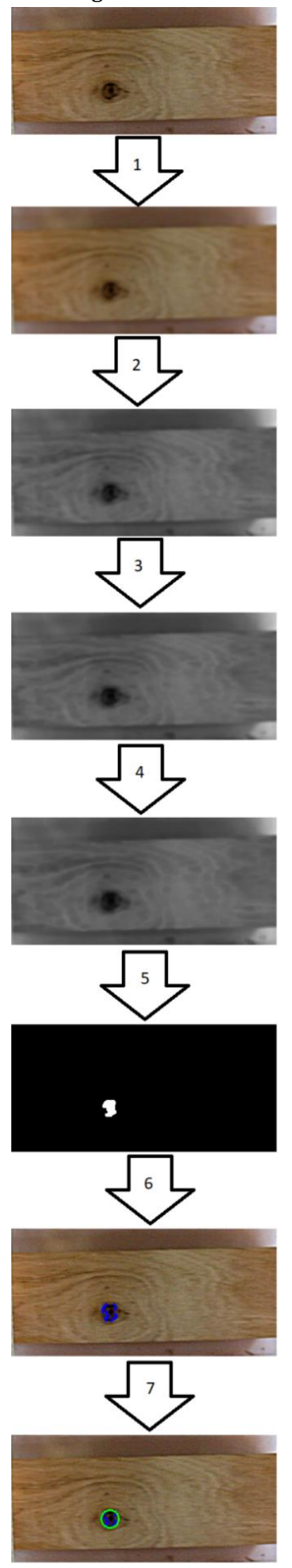

Figure 5. Knot Detection Steps. 
The second step; grayscaling is a common practice used in image processing to simplify processing tasks when color information is not vital. Knot defect detection may be done in grayscale and should not be color-dependent, as the color tones change by to element's tree type and knot features are morphological and not color related. Grayscaling of element image is done according to ITU-R (Radiocommunication Sector of International Telecommunication Union) recommendation BT.601-7 [39]. In Figure 5 Step 2, grayscaled element image is shown.

The third and fourth steps employ vertical and horizontal image erosions to reduce noise and detection adversities due to the tree growth rings and cracks. Image erosion is applied to remove noisy connections between objects [40]. In the wooden element case, its application contributes to easier differentiation of knots by increasing gaps between and thinning down growth rings. Our experiments resulted in erosion matrix sizes of 3x1 and 1x3 gave optimal results. In Figure 5 Step 3 and Step 4, vertically and horizontally eroded element images are shown.

In the fifth step, the histogram thresholding method is used to identify all knot defect candidates. This method allows detection of pixels that are darker than a threshold in grayscale such as the surface average tone. Given knot defects are rare and darker regions, a threshold value corresponding to pixels covering darkest $0.5 \%$ of all pixels on the element image is used. Lower and higher threshold values are tried but adversely affected the knot detection performance. Figure 5 Step 5 shows the application of histogram thresholding. Note that a knot defect candidate; white region, has been detected at this point.

In the sixth step, knot defects are identified from the list of candidates highlighted after histogram thresholding in the fifth step. A knot defect candidate, at this point, is a white region. First knot candidates are filtered based on a size if they are within tolerable range by wooden panel manufacturer (>90 pixels). Next, as knots are circular in nature, the circularity of the defect candidate, as shown in Equation (1) is measured by computing the ratio between the area of defect candidate and the area of the minimum enclosing circle which is calculated using the Welzl's algorithm [41]. The candidate is labeled as a knot defect if it has circular morphology. Figure 5 Step 6 shows a knot defect identified in this step.

$$
\text { area(defect_candidate)/area(min_enclosing_circle) }
$$

In the seventh step, knot defects are marked on the original (color) element surface images using minimum enclosing circles in yellow as seen in Figure 5 Step 7.

\section{Results}

In Turkey, there are many wooden panel manufacturing companies, which not only meet the domestic demand but also positively contribute to the economy with their sizable exports. The absence of an automated element quality control system and the reliance on a humanbased quality control system are adversely affecting the quality of their end-product; wooden panels. An automated system will enable the manufacturers to improve their production quality and to minimize the losses due to low-quality wooden panels.

In this study, we first identified the quality issues in the current production process of the Turkish wooden panel industry. Then, we developed a prototype system to automatically detect knot defects on the elements; the major input for the wooden panel manufacturing process. Section 4 explains the knot defect detection algorithm in detail.

The prototype was tested on 100 element surfaces, manually tagged (50 with knot defect or positive, and 50 without knot defect or negative by the experts of the wooden panel manufacturing company). This element image library made publicly available to support similar studies in the future.

\begin{tabular}{|c|c|c|c|}
\hline & & \multicolumn{2}{|c|}{ Element Surface } \\
\hline & & $\begin{array}{c}\text { Positive } \\
\text { (with knot defect) }\end{array}$ & $\begin{array}{c}\text { Negative } \\
\text { (w/o knot defect) }\end{array}$ \\
\hline $\begin{array}{l}\mathrm{D} \\
\mathrm{e} \\
\mathrm{t} \\
\mathrm{e}\end{array}$ & Positive & $\begin{array}{c}40 \\
\text { (True Positive) }\end{array}$ & $\begin{array}{c}9 \\
\text { (False Positive) }\end{array}$ \\
\hline $\begin{array}{l}\mathrm{t} \\
\mathrm{i} \\
\mathrm{o} \\
\mathrm{n}\end{array}$ & Negative & $\begin{array}{c}10 \\
\text { (False Negative) }\end{array}$ & $\begin{array}{c}41 \\
\text { (True Negative) }\end{array}$ \\
\hline
\end{tabular}

Table 1 summarizes the performance of the prototype. The system achieved $80.0 \%$ true positive rate (40 out of 50 elements with knot defects) and $82.0 \%$ true negative rate (41 out of 50 elements without knot defects. Overall accuracy was $81.0 \%$ (81 correct detection in 100 elements). As per discussions we had with industry representatives, on average, these performance rates are comparable to human quality control inspectors.

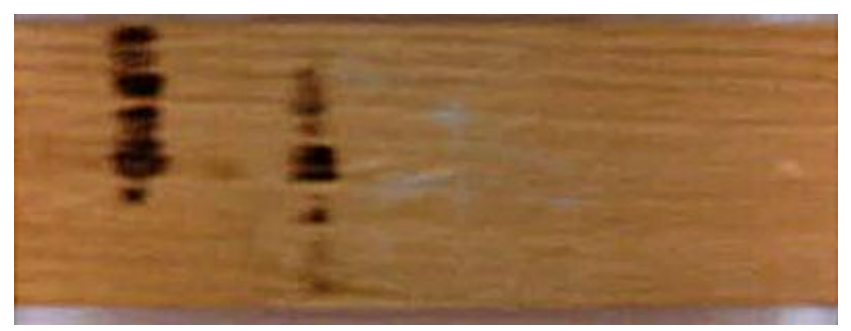

Figure 6. Surface with a cut burn.

We further inspected false negative and false positive detections. Majority of the false negatives were due to the location of the knots. As elements have thin and long surfaces, some partial knots were located on the edges and do not have circular shapes. Therefore, these knots are not detected by the system. On the other hand, false positives were primarily due to the friction burns 
formed during the element cutting process (See Figure 6). In addition, factors such as crack, split, which add depth to the surface, affect the color distribution, and these results lead to false knot detection.

\section{Conclusion}

In this study, quality problems faced by companies in the wooden panel industry and challenges encountered during the application of image processing techniques in the wooden panel quality control are analyzed. Furthermore, a prototype to detect knots defects, the most common flaws in wooden panel manufacturing, has been developed. This prototype achieves a knotdetection performance equivalent to a human quality control inspector. To support similar studies, the dataset used in testing the prototype made publicly available at http://eng1.mu.edu.tr/KnotDetectionDataSet/.

In the future, we plan to improve this prototype system in two major ways. First, there is room for improvement of knot-detection accuracy by factoring in burn and edge knots. The current prototype is developed only to detect knot defects. Hence, as a second improvement, we plan to enhance the current system with modules supporting morphological operations to detect defects other than knots, which are analyzed as part of this study and detailed in section 2.2.1.

\section{References}

[1] Masif Panel Nedir. Available: http://www.bilenor.com.tr/default.aspx?pid=6295 $3 \&$ nid $=60387$

[2] Dilek, T., Erdinler, E.S. and Öztürk, E., "Masif panel ve sektörel gelişiminin incelenmesi". İkinci Ulusal Mobilya Kongresi, Denizli, Türkiye, 11-13 Nisan 2013

[3] Ade, F., Lins, N. and Unser, M., "Comparison of various filter sets for defect detection in textiles". Seventh International Conference on Pattern Recognition, Montreal, Canada, July 30 - August 2 1984.

[4] Baykut, A., Atalay, A., Ercil, A. and Guler, M., "Realtime defect inspection of textured surfaces". RealTime Imaging, 6(1), 17-27, 2000.

[5] Conci, A. and Proenca, C.B., "A system for real-time fabric inspection and industrial decision". Fourteenth International Conference on Software Engineering and Knowledge Engineering, Ischia, Italy, 15-19 July 2002.

[6] Kumar, A., "Neural network based detection of local textile defects". Pattern Recognition, 36(7), 16451659, 2003.

[7] Costa, C.E. and Petrou, M., "Automatic registration of ceramic tiles for the purpose of fault detection". Machine Vision and Applications, 11(5), 225-230, 2000.

[8] Shire, A.N., Khanapurkar, M.M. and Mundewadikar, R.S., "Plain ceramic tiles surface defect detection using image processing". Fourth International Conference on Emerging Trends in Engineering and
Technology, Port Louis, Mauritius, 18-20 November 2011.

[9] Boukouvalas, C. and Petrou, M., "Perceptual correction for colour grading of random textures". Machine Vision and Applications, 12(3), 129-136, 2000.

[10] Pernkopf, F., "Detection of surface defects on raw steel blocks using Bayesian network classifiers". Pattern Analysis and Applications, 7(3), 333-342, 2004.

[11] Wiltschi, K., Pinz, A. and Lindeberg, T., "An automatic assessment scheme for steel quality inspection". Machine Vision and Applications, 12(3), 113-128, 2000.

[12] Peng, X., Chen, Y., Yu, W., Zhou, Z. and Sun G., "An online defects inspection method for float glass fabrication based on machine vision". International Journal of Advanced Manufacturing Technology, 39(11-12), 1180-1189, 2008.

[13] Mar, N.S.S., Fookes, C. and Yarlagadda, P.K.D.V., "Design of automatic vision-based inspection system for solder joint segmentation". Journal of Achievements in Materials and Manufacturing Engineering, 34(2), 145-151, 2009.

[14] Li, Y., Li, Y.F., Wang, Q.L., Xu, D. and Tan, M., "Measurement and defect detection of the weld bead based on online vision inspection". IEEE Transactions on Instrumentation and Measurement, 59(7), 1841-1849, 2010.

[15] Kamal, I.A. and Al-Alaoui, M.A. "Online machine vision inspection system for detecting coating defects in metal lids". International MultiConference of Engineers and Computer Scientists, Hong Kong, China, 19-21 March 2008.

[16] Laurowski, M., Klein, P.H., Weyrich, M., Scharf, P. and Stark, S., "Use-appropriate design of automated optical inspection systems for rotationally symmetric parts". 56th International Scientific Colloquium, Ilmenau, Germany, 12 - 16 September 2011.

[17] Nacy, S.M. and Abbood, W.T., "Automated surface defect detection using area scan camera". Innovative Systems Design and Engineering, 4(8), 1$10,2013$.

[18] Xie, X., "A review of recent advances in surface defect detection using texture analysis techniques". Electronic Letters on Computer Vision and Image Analysis, 7(3), 1-22, 2008.

[19] Jabo, S., Machine Vision for Wood Defect Detection and Classification. MSc Thesis, Chalmers University of Technology, Göteborg, Sweden, 2011.

[20] Kline, D.E., Hou, Y.J., Conners, R.W., Schmoldt, D.L. and Araman P.A., "Lumber scanning system for surface defect detection". American Society of Agricultural Engineers International Winter Meeting, Nashville, Tennessee, USA, 15-18 December 1992. 
[21] Mohan, S. and Venkatachalapathy, K., "Wood knot classification using bagging". International Journal of Computer Applications, 51(18), 50-53, 2012.

[22] Hu, C., Min, X., Yun, H., Wang, T. and Zhang, S., "Automatic detection of sound knots and loose knots on sugi using gray level co-occurrence matrix parameters". Annals of Forest Science, 68 (6), 1077 1083, 2011.

[23] WEINIG scanner systems. Available: https://www.weinig.com/en/solid-wood/scannersystems.html

[24] GreCon SUPERSCAN SPM/L. Available: https://www.fagusgrecon.com/en/solutions/measuringtechnology/superscan-ml/

[25] ColourBrain ${ }^{\circledR} \quad$ Panel. Available: http://www.baumerinspection.com/en/products/s urface-inspection/colourbrainr-panel.html

[26] TS 11970 EN 13990 standardları. Available: https://intweb.tse.org.tr/Standard/Standard/Stand ard.aspx?08111805111510805110411911010405 5047105102120088111043113104073088108051 048054053122098066110072

[27] Record, S.J., The Mechanical Properties of Wood. 1st ed. New York, USA, J. Wiley \& sons, 1914.

[28] Visual Inspection of Lumber. Available: http://www.ee.oulu.fi/ olli/Projects/Lumber.Grad ing.html

[29] Lowe, D.G., "Distinctive image features from scaleinvariant Keypoints". International Journal of Computer Vision, 60(2), 91-110, 2004.

[30] OpenCV (Open Source Computer Vision Library). Available: http://opencv.org

[31] Stier, J. and Beilschmidt, M., "Generating train side views from video sequences for microphone array pass-by measurements". Fourth Berlin Beamforming Conference, 22-23 February 2012.

[32] Jianhua, Y., Var, A.A., X'ao, J., Fu, W., Chen, J., Yan, L. and Wang S., "Image processing and identification of lumber surface knots". Acta Technica, 62(1A), 99108, 2017.

[33] Haralick, R., Shanmugan, K. and Dinstein, I., "Textural features for image classification". IEEE
Transactions on Systems, Man, and Cybernetics, 3(6), 610-621, 1973.

[34] Conners, R., McMillan, C., Lin, K. and VasquezEspinosa, R., "Identifying and locating surface defectsin wood: Part of an automated timber processing system". IEEE Transactions on Pattern Analysis and Machine Intelligence, 5(6), 573-583, 1983.

[35] Otsu, N., "An automatic threshold selection method based on discriminate and least squares criteria (in Japanese)". Denshi Tsushin Gakkai Ronbunshi, 63, 349-356, 1979.

[36] Gabor, D., "Theory of communication". Journal of the Institution of Electrical Engineers, 93, 429-441, 1946.

[37] Daugman, J.G., "Uncertainty relation for resolution in space, spatial-frequency, and orientation optimized by two-dimensional visual cortical filters". Journal of the Optical Society of America A: Optics, Image Science, and Vision, 2(7), 1160-1169, 1985.

[38] Chacon, M.I. and Alonso, G.R., "Wood defects classification using a SOM/FFP approach with minimum dimension feature vector". Third International Symposium on Neural Networks, Chengdu, China, May 28 - June 12006.

[39] ITU-R BT.601, Recommendation BT.601-7 (03/2011): Studio encoding parameters of digital television for standard 4:3 and wide screen 16:9 aspect ratios.

[40] Srisha, R. and Khan, A. (2013). "Morphological Operations for Image Processing : Understanding and its Applications". National Conference on VLSI, Signal processing and Communications, Vignan University, Guntur, India, 11-12 December 2013

[41] Welzl, E., "Smallest enclosing disks (balls and ellipsoids)", in Maurer, H., New Results and New Trends in Computer Science, Lecture Notes in Computer Science, vol 555, pp. 359-370, Springer, Berlin, Heidelberg, 1991. 